\title{
Alterações do sono em professores universitários: uma revisão integrativa
}

\author{
Sleep disorders in university professors: an integrative review
}

Bruno Fernando Moneta Moraes ${ }^{1}$

Orcid: https://orcid.org/0000-0001-8590-5746

\author{
Carolina Pasquini Praxedes Salvi ${ }^{2}$ \\ Orcid: https://orcid.org/0000-0002-2998-1522
}

Milva Maria Figueiredo De Martino ${ }^{3}$

Orcid: https://orcid.org/0000-0002-3877-4218

\begin{abstract}
Resumo
Introdução: Professores universitários, de diversas áreas do conhecimento, constantemente, agregam, além de sua carga horária frente ao aluno, tarefas extraclasse que alongam sua jornada laboral, múltiplos empregos e execução de tarefas em prazos reduzidos. Diante disso, esses profissionais podem apresentar quadros negativos em relação ao seu sono, incluindo sua privação e redução da sua qualidade, impactando em seu bem-estar e saúde. Objetivo: evidenciar as principais alterações do sono em professores universitários, salientando os fatores associados e as repercussões dessas ocorrências. Materiais e métodos: revisão integrativa realizada nos portais PubMed, Web of Science, Scopus, CINAHL e Biblioteca Virtual em Saúde, utilizando-se os descritores Faculty, Sleep Deprivation, Dyssomnias, Sleep Wake Disorders e Sleepiness, além do termo livre Sleep Quality, com estudos originais publicados entre 2002 e 2021, nos idiomas português, inglês e espanhol. Resultados: foram eleitos cinco estudos, realizados no Brasil (80,0\%) e China (20,0\%), entre 2018 e 2021, com desenho transversal $(100,0 \%)$, nível de evidência $4(100,0 \%)$, os quais mostraram que as alterações do sono em professores universitários caracterizaram-se por redução da qualidade subjetiva do sono e sonolência diurna. Conclusões: Aspectos relacionados ao trabalho do professor universitário influenciaram na qualidade do sono, como jornadas extensas, o trabalho excessivo, workaholism e a alta exigência no trabalho. A redução na qualidade do sono e a sonolência diurna repercutiram nas percepções de qualidade de vida e em aspectos ligados ao Burnout. Torna-se imprescindível a busca por dados científicos robustos, explorando amplamente as alterações de sono em professores universitários e monitorando suas repercussões.
\end{abstract}

Palavras-chave: docentes; privação do sono; dissonias; transtornos do sono-vigília; qualidade do sono. sonolência.

\begin{abstract}
Introduction: University professors, from different areas of knowledge, constantly add, in addition to their workload in front of the student, extra-class tasks that lengthen their working hours, multiple jobs and execution of tasks in reduced terms. Therefore, these professionals may present negative pictures in relation to their sleep, including their deprivation and reduction in its quality, impacting their well-being and health. Objective: highlight the main sleep changes in university professors, evidencing the associated factors and the repercussions of these occurrences. Materials and methods: integrative review carried out on the PubMed, Web of Science, Scopus, CINAHL and Virtual Health Library portals, using the descriptors Faculty, Sleep Deprivation, Dyssomnias, Sleep-Wake Disorders and Sleepiness, in addition to the free term Sleep Quality, with original articles published between 2002 and 2021, in Portuguese, English and Spanish. Results: five studies were chosen, carried out in Brazil
\end{abstract}

\footnotetext{
${ }^{1}$ Universidade Estadual de Campinas - Unicamp. Brasil. E-mail: bruno-fernando@uol.com.br

${ }^{2}$ Universidade Estadual de Campinas - Unicamp. Brasil. E-mail: carolpraxedes@yahoo.com.br

${ }^{3}$ Universidade Estadual de Campinas - Unicamp. Brasil. E-mail: milva@unicamp.br
} 
(80.0\%) and China (20.0\%), between 2018 and 2021, with a cross-sectional design (100.0\%), level of evidence $4(100.0 \%)$, what are the characteristics that sleep changes in university professors characterized by reduced sleep quality and daytime sleepiness. Conclusions: Aspects related to the work of university professors lead to sleep quality, such as long hours, excessive work, workaholism and high demand at work. The reduction in sleep quality and daytime sleepiness had an impact on perceptions of quality of life and aspects related to Burnout. A search for robust scientific data is essential, exploring broadly how sleep changes in university professors and monitoring their repercussions.

Keywords: faculty; sleep deprivation; dyssomnias; sleep wake disorders; sleep quality; sleepiness.

\section{Introdução}

A atividade laboral de um docente compreende uma complexa função por sua ampla importância social e o seu papel formativo, bem como pela necessidade de adaptações constantes a novas realidades, desafios e inovações ${ }^{1}$. Trata-se de uma profissão caracterizada por constantes tensões emocionais e mentais, agravada, muitas vezes, por condições ambientais adversas, ausência de perspectivas de crescimento e ascensão profissional, além de problemas pessoais ${ }^{2}$.

Professores universitários, constantemente, agregam, além de sua carga horária frente ao aluno, tarefas extraclasse que alongam sua jornada laboral, múltiplos empregos e execução de tarefas em prazos reduzidos, bem como lidar com as relações interpessoais com alunos e com colegas e lideranças universitárias ${ }^{3-4}$. Ainda, de acordo com a atividade acadêmica desenvolvida, a busca de produtividade científica nas atuações stricto sensu passou exigir que os docentes admitam um caráter resolutivo e imediatista, atentos a evoluções e atualizações constantes, estendendo cada vez mais a jornada de trabalho e produzindo cenários desfavoráveis à saúde ${ }^{5-6}$.

Diante disso, docentes universitários de diversas áreas do conhecimento podem apresentar quadros negativos em relação ao seu sono, incluindo sua privação e redução da sua qualidade. $\mathrm{O}$ sono é um estado biológico reversível, recorrente, em que o indivíduo apresenta relativa imobilidade e perda de percepção ambiental. Trata-se de período altamente necessário para manutenção e restauração energética e reorganização das informações neurológicas, contribuindo para a recuperação dos recursos mentais, preparando o indivíduo para o período de vigília ${ }^{7}$.

De acordo com a Sleep Foundation (organização norte-americana, sem fins lucrativos, para pesquisa e práticas na saúde do sono) o sono é fundamental para a boa saúde e sua qualidade conceitua-se como "a satisfação de um indivíduo com seu sono, integrando aspectos da iniciação do sono, manutenção do sono, quantidade de sono e sensação de revigoramento ao acordar" Prejuízos à qualidade do sono desencadeiam respostas orgânicas que modificam a função cognitiva, comportamental, psicomotora, bem como pode prejudicar o humor, elevar os níveis de estresse, sensação de cansaço e desânimo e outras condições que comprometem a saúde e a qualidade de vida ${ }^{9}$.

Entre professores universitários, a redução da qualidade do sono, bem como seus efeitos benéficos como a recuperação mental e física, impacta diretamente em seu bem-estar e qualidade de vida, podendo desencadear quadros de estresse laboral, tendências alimentares prejudiciais e sintomas de Burnout, cuja definição referese a uma síndrome psicossocial surgida como uma resposta crônica aos estressores interpessoais ocorridos na situação de trabalho ${ }^{10}$. Todos esses fatores somados podem repercutir em sua saúde física e mental, bem como no seu comportamento neurocognitivo, afetando diretamente o seu desempenho laboral ${ }^{1,4,11,12}$, consequências extremamente ameaçadoras, as quais 
podem se tornar uma questão de saúde pública.

Embora existam vários estudos recentes com estas variáveis, nota-se que, especificamente entre os professores universitários, ainda existe uma lacuna no que tange a um diagnóstico situacional. Nesse contexto, evidenciar a ocorrência de distúrbios do sono nessa população, bem como suas principais causas e repercussões diretas e indiretas torna-se de extrema relevância, não só para a implementação de condições que favoreçam a saúde desses trabalhadores, mas, também, para mitigar possíveis consequências ao exercício da profissão. Objetivou-se, portanto, neste estudo, evidenciar as principais alterações do sono em professores universitários, salientando os fatores associados e as repercussões dessas ocorrências.

\section{Materiais e Métodos}

\section{Amostra e tipo de estudo}

Trata-se de um estudo de revisão integrativa com a finalidade de responder a seguinte questão de pesquisa: "Quais são as alterações do sono mais comuns em professores universitários, bem como as suas causas e possíveis repercussões?". Essa questão norteadora foi formulada com base na estratégia $\mathrm{PICO}^{13}$. Desse modo, definiu-se para este estudo: $\mathrm{P}$ - professores universitários; I - principais alterações do sono em professores universitários; $\mathrm{C}$ - não se aplica neste estudo, por não haver processos comparativos; $\mathrm{O}-$ fatores associados e repercussões das alterações do sono nessa população.

\section{Delineamento da pesquisa}

A elaboração deste estudo a partir de pesquisas originais, observacionais e transversais, seguiu o procedimento preconizado de seis etapas: identificação do tema e seleção da hipótese, estabelecimento da estratégia de pesquisa, definição e coleta de dados, análise dos dados coletados, interpretação e apresentação dos resultados $^{14,15}$. A revisão do processo baseou-se nas recomendações da lista de conferência Preferred Reporting Items for Systematic Reviews and Meta-Analyses (PRISMA) ${ }^{16}$.

Realizou-se a busca e seleção de evidências científicas por dois revisores, de forma simultânea, entre os meses de junho a agosto de 2021, nas bases de dados Medical Literature Analysis and Retrieval System Online (MEDLINE) via National Library of Medicine (PubMed), Scopus, Web of Science (WoS), e CINAHL via EBSCOHost, além da Biblioteca Virtual em Saúde (BVS). Utilizaram-se os descritores padronizados no MeSH Terms: "Faculty", "Sleep Deprivation", "Dyssomnias", "Sleep Wake Disorders" e "Sleepiness", além do termo livre "Sleep Quality", bem como seus sinônimos. Para a busca avançada para cada termo utilizou-se o operador booleano "OR" entre eles, contemplando todos os sinônimos. Para os cruzamentos entre os termos, empregou-se o operador booleano "AND".

Não foram aplicados filtros para identificar todos os artigos disponíveis nas bases e reduzir o risco de viés de publicação, com exceção do recorte temporal dos últimos 20 anos (2002 a 2021). A leitura e seleção dos artigos foi realizada por dois revisores de forma independente, por meio da plataforma de seleção on-line Rayyan QCR ${ }^{17}$, iniciandose pelos títulos, seguida dos resumos e textos. Na seleção dos títulos foram incluídos todos os que apresentaram o termo "professores" ou "sono" ou qualquer sinônimo relacionado. Quando a aplicação dos critérios de elegibilidade não foi suficiente para estabelecer se o artigo seria incluído ou não em uma etapa, o mesmo foi mantido para leitura do resumo. A última etapa da seleção foi procedida por meio da leitura do texto completo dos artigos.

\section{Critérios de Inclusão e Exclusão}


Para esta revisão, foram incluídos estudos realizados exclusivamente com professores universitários, publicados nos últimos vinte anos, em inglês, português ou espanhol, com fortes evidências de má qualidade ou demais alterações do sono e suas repercussões e relações com demais variáveis, demonstradas por instrumentos de autorresposta ou ainda por polissonografia ou actigrafia. Excluíram-se séries e relatos de casos, estudos de revisão e resumos de congressos, pesquisas qualitativas e estudos indisponíveis na íntegra. Ainda, excluíram-se os artigos em duplicidade, artigos pertencentes a recortes de pesquisas de uma mesma população contida num artigo previamente incluído e estudos que abordavam as características do sono em preceptores de residência médica ou similar.

\section{Critérios de qualidade}

Quadro 1 - Avaliação da qualidade metodológica de acordo com o checklist JBI ${ }^{18}$ para estudos transversais. Campinas, São Paulo, Brasil - 2021. $(\mathrm{n}=5)$

\begin{tabular}{|l|c|c|c|c|c|}
\hline \multicolumn{1}{|c|}{ Checklist JBI / Estudos Incluídos } & $\begin{array}{c}\text { Cardoso, } \\
\mathbf{2 0 2 0}\end{array}$ & $\begin{array}{c}\text { Sousa, } \\
\mathbf{2 0 1 8}\end{array}$ & $\begin{array}{c}\text { Amaro, } \\
\mathbf{2 0 1 8}\end{array}$ & $\begin{array}{c}\text { Wu, } \\
\mathbf{2 0 2 0}\end{array}$ & $\begin{array}{c}\text { Freitas, } \\
\mathbf{2 0 2 1}\end{array}$ \\
\hline $\begin{array}{l}\text { 1. Os critérios de inclusão na amostra } \\
\text { foram claramente definidos? }\end{array}$ & $\operatorname{Sim}$ & $\operatorname{Sim}$ & $\operatorname{Sim}$ & Sim & Sim \\
\hline $\begin{array}{l}\text { 2. Os sujeitos do estudo e o ambiente } \\
\text { foram descritos em detalhes? }\end{array}$ & Sim & Sim & Sim & Sim & Sim \\
\hline $\begin{array}{l}\text { 3. A exposição foi medida de forma } \\
\text { válida e confiável? }\end{array}$ & $\operatorname{Sim}$ & $\operatorname{Sim}$ & $\operatorname{Sim}$ & Sim & Sim \\
\hline $\begin{array}{l}\text { 4. Foram usados critérios objetivos e } \\
\text { padronizados para a medição da } \\
\text { condição? }\end{array}$ & Sim & Sim & Sim & Sim & Sim \\
\hline $\begin{array}{l}\text { 5. Foram identificados fatores de } \\
\text { confusão? }\end{array}$ & Sim & Sim & Sim & Sim & $\begin{array}{c}\text { Pouco } \\
\text { Claro }\end{array}$ \\
\hline
\end{tabular}




\begin{tabular}{|l|c|c|c|c|c|}
$\begin{array}{l}\text { 6. Foram estabelecidas estratégias para } \\
\text { lidar com fatores de confusão? }\end{array}$ & $\operatorname{Sim}$ & Não & Não & $\begin{array}{c}\text { Pouco } \\
\text { Claro }\end{array}$ & $\begin{array}{c}\text { Pouco } \\
\text { Claro }\end{array}$ \\
\hline $\begin{array}{l}\text { 7. Os resultados foram medidos de forma } \\
\text { válida e confiável? }\end{array}$ & $\operatorname{Sim}$ & $\operatorname{Sim}$ & $\operatorname{Sim}$ & $\operatorname{Sim}$ & $\operatorname{Sim}$ \\
\hline $\begin{array}{l}\text { 8. Foi usada uma análise estatística } \\
\text { apropriada? }\end{array}$ & $\operatorname{Sim}$ & $\operatorname{Sim}$ & $\begin{array}{c}\text { Pouco } \\
\text { Claro }\end{array}$ & $\operatorname{Sim}$ & $\operatorname{Sim}$ \\
\hline
\end{tabular}

Fonte: elaboração própria.

\section{Procedimentos}

Realizou-se a extração dos dados dos estudos incluídos na amostra com auxílio de uma planilha, previamente planejada, contendo as seguintes informações: autoria, ano de publicação, período da coleta dos dados, local do estudo, amostra (n), instrumentos de avaliação de alterações do sono, outras variáveis estudadas e desfecho. Não houve necessidade de aprovação do projeto do estudo em Comitê de Ética em Pesquisa por se tratar de revisão integrativa com busca por evidências científicas publicadas em bases de dados.

Totalizaram-se 2201 artigos para análise. Utilizou-se como estratégia para a seleção a leitura dos títulos e, de acordo com estes, a análise dos resumos da amostra total, levando-se em consideração os critérios de inclusão e exclusão. Assim, do total de 2201 artigos encontrados, compuseram a amostra final cinco artigos. $O$ apêndice 1 evidencia a estratégia de busca nas bases de dados e a figura 1 ilustra os passos para a seleção, adaptado do PRISMA Statement ${ }^{16}$. 
Figura 1: Fluxograma do processo de seleção dos artigos. Campinas, São Paulo, Brasil - 2021.

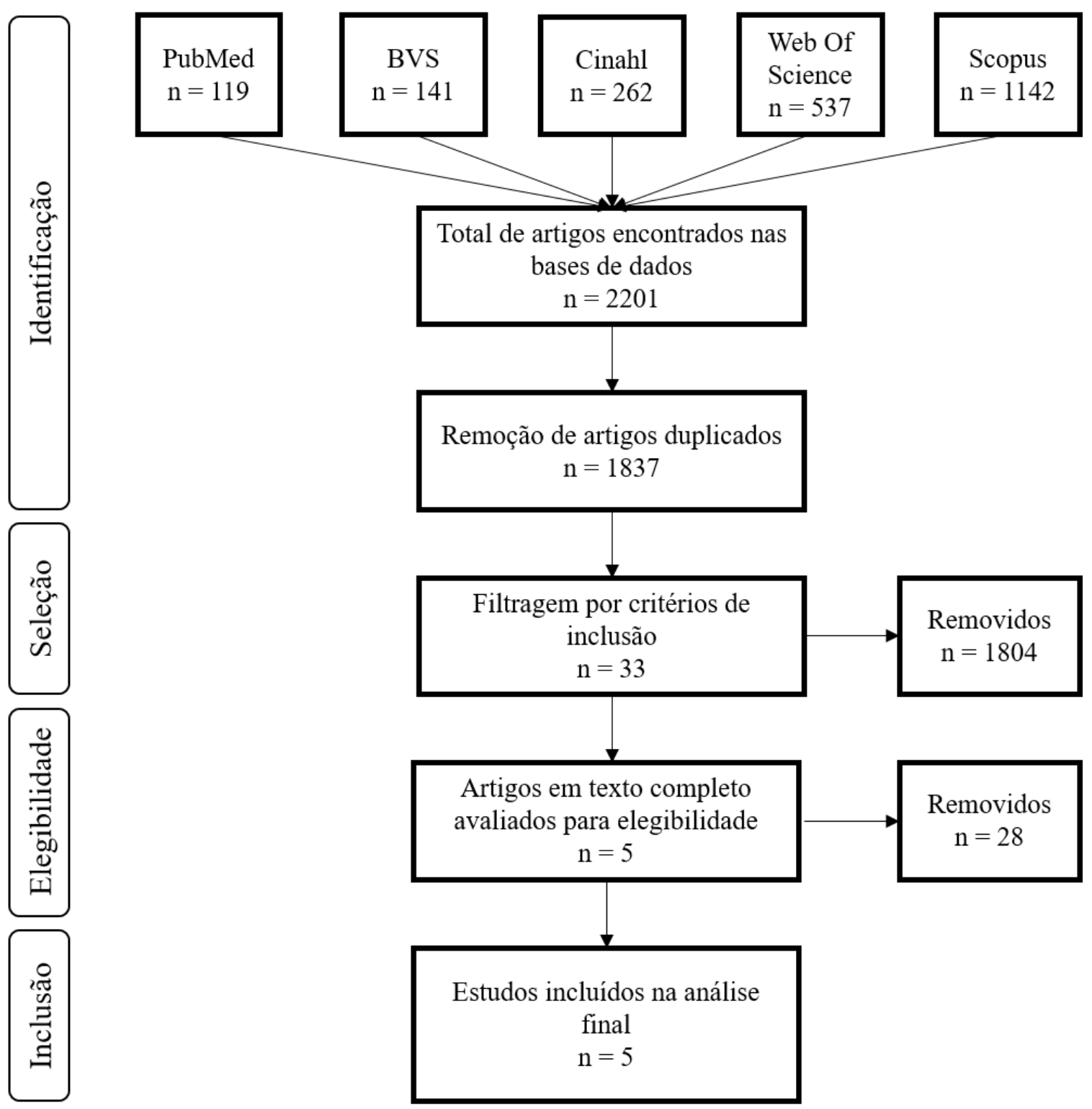

Fonte: Elaboração própria, adaptado de PRISMA Statement ${ }^{14}$.

Após a seleção da amostra final, classificou-se o nível de evidência com base no desenho de pesquisa de cada artigo. A estratificação empregada apresenta seis níveis: são classificados em nível 1 os resultados provenientes de meta-análise de múltiplos estudos clínicos controlados e randomizados; em nível 2, evidências resultantes de estudos individuais com delineamento experimental; em nível 3, resultados de estudos quase-experimentais; em nível 4, evidências de estudos descritivos, incluindo-se os transversais, ou com abordagem qualitativa; em nível 5, relatos de caso ou de experiência; e, em nível 6 , as evidências baseadas em opiniões de especialistas ${ }^{19}$. 


\section{Resultados}

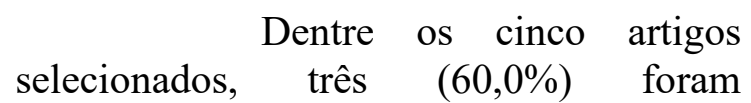
publicados em português e dois $(40,0 \%) \mathrm{em}$ inglês, não havendo artigos em espanhol. Quanto à origem geográfica do estudo, quatro $(80,0 \%)$ foram realizados no Brasil e apenas um $(20,0 \%)$ na China. Observou-se que os periódicos que trouxeram publicações eram da área da Enfermagem $(40,0 \%)$, Psiquiatria $(40,0 \%)$ e Saúde Ocupacional (20,0\%). Embora o recorte temporal tenha agregado as publicações dos últimos 20 anos, nota-se o caráter recente dos estudos elegíveis para esta revisão, sendo que, dois foram publicados em 2018 $(40,0 \%)$, dois em $2020(40,0 \%)$ e um em $2021(20 \%)$.

A tabela 1 evidencia o delineamento, bem como a classificação do nível de evidência dos estudos. Devido ao fato de a amostra ser composta apenas por estudos transversais, todos foram classificados com nível de evidência $4^{19}$.

Tabela 1: Delineamento e nível de evidência ${ }^{19}$ dos estudos que compuseram esta revisão. Campinas, São Paulo, Brasil - 2021. $(\mathrm{n}=5)$

\begin{tabular}{ccc}
\hline Estudo & Delineamento & Nível de Evidência \\
\hline Cardoso, 2020 & Transversal & 4 \\
Sousa, 2018 & Transversal & 4 \\
Amaro, 2018 & Observacional, Transversal & 4 \\
Wu, 2020 & Transversal & 4 \\
Freitas, 2021 & Expidemiológico, Transversal, & 4 \\
& Exploratório & 4 \\
\hline
\end{tabular}

Fonte: Elaboração Própria.

Para a análise dos aspectos relacionados ao sono, três estudos $(60,0 \%)^{20,21,23}$ utilizaram o Pittsburgh Sleep Quality Index (PSQI), enquanto os demais aplicaram a Escala de Sonolência de Epworth (ESS) $(20,0 \%)^{22}$ e o Mini-Sleep Questionnaire (MSQ) $\quad(20,0 \%)^{24}$, respectivamente. Ademais, todos os estudos relacionaram os dados de sono a variáveis independentes, dados demográficos e ocupacionais, de acordo com seus objetivos. As variáveis independentes foram o workaholism $^{20}$, estresse $^{21}$, qualidade de $\operatorname{vida}^{22}$, Burnout e polimorfismo genômico ${ }^{23}$.

O quadro 2 traz uma descrição dos títulos e autoria, bem como o ano de publicação, objetivos e uma síntese dos resultados de cada estudo eleito para esta revisão. 


\begin{tabular}{|c|c|c|c|c|}
\hline Título & $\begin{array}{c}\text { Primeiro } \\
\text { Autor (Ano) }\end{array}$ & População & Objetivos & Conclusão \\
\hline $\begin{array}{l}\text { Qualidade do sono } \\
\text { e workaholism em } \\
\text { docentes de pós- } \\
\text { graduação stricto } \\
\text { sensu }^{17}\end{array}$ & $\begin{array}{c}\text { Mariana } \\
\text { Guimarães } \\
\text { Cardoso } \\
(2020)\end{array}$ & $\begin{array}{l}196 \text { docentes } \\
\text { de pós- } \\
\text { graduação } \\
\text { stricto sensu }\end{array}$ & $\begin{array}{c}\text { Investigar a } \\
\text { associação entre a } \\
\text { qualidade do sono } \\
\text { e o workaholism } \\
\text { em docentes de } \\
\text { pós-graduação } \\
\text { stricto sensu }\end{array}$ & $\begin{array}{l}\text { As altas demandas de trabalho } \\
\text { podem estar associadas à qualidade } \\
\text { do sono ruim, pois foi constatado } \\
\text { que os docentes workaholics e com } \\
\text { alto trabalho excessivo } \\
\text { apresentaram chances aumentadas } \\
\text { de má qualidade do sono, mesmo } \\
\text { após ajustes. A qualidade subjetiva } \\
\text { do sono, bem como a latência do } \\
\text { sono, duração do sono, distúrbios } \\
\text { do sono e sonolência diurna, } \\
\text { tiveram associação com o } \\
\text { workaholism, trabalho excessivo e } \\
\text { compulsivo. }\end{array}$ \\
\hline $\begin{array}{c}\text { Occupational } \\
\text { stress and sleep } \\
\text { quality in } \\
\text { professors of the } \\
\text { health area }{ }^{18}\end{array}$ & $\begin{array}{l}\text { Aline } \\
\text { Rodrigues de } \\
\text { Sousa (2018) }\end{array}$ & $\begin{array}{l}19 \text { docentes } \\
\text { universitários } \\
\text { da área da } \\
\text { saúde }\end{array}$ & $\begin{array}{l}\text { Analisar a relação } \\
\text { entre estresse } \\
\text { ocupacional e } \\
\text { qualidade do sono } \\
\text { em professores da } \\
\text { área da saúde }\end{array}$ & $\begin{array}{l}\text { Houve predomínio de baixo nível } \\
\text { de estresse e má qualidade do sono, } \\
\text { sendo a sonolência diurna, os } \\
\text { distúrbios do sono e a duração do } \\
\text { sono os fatores que mais } \\
\text { contribuíram para a má qualidade } \\
\text { do sono dos professores da saúde. } \\
\text { A diminuição da qualidade do sono } \\
\text { relacionada ao uso de medicação } \\
\text { para dormir resultou em maiores } \\
\text { níveis de estresse ocupacional entre } \\
\text { os docentes. }\end{array}$ \\
\hline $\begin{array}{l}\text { Sonolência diurna } \\
\text { excessiva e } \\
\text { qualidade de vida } \\
\text { relacionada à } \\
\text { saúde dos } \\
\text { professores } \\
\text { universitários }^{19}\end{array}$ & $\begin{array}{c}\text { João Marcelo } \\
\text { Ramachiotti } \\
\text { Soares } \\
\text { Amaro } \\
(2018)\end{array}$ & $\begin{array}{c}270 \text { professores } \\
\text { universitários }\end{array}$ & $\begin{array}{c}\text { Analisar a } \\
\text { influência da } \\
\text { sonolência diurna } \\
\text { excessiva na } \\
\text { qualidade de vida } \\
\text { dos docentes }\end{array}$ & $\begin{array}{l}\text { Foram encontradas associações } \\
\text { estatisticamente significativas para } \\
\text { sonolência diurna excessiva com } \\
\text { menor escore de qualidade de vida } \\
\text { em todos os domínios investigados. } \\
\text { Além disso, destaca-se que um de } \\
\text { cada três professores foram } \\
\text { identificados com sonolência diurna } \\
\text { excessiva. }\end{array}$ \\
\hline $\begin{array}{l}\text { Burnout in } \\
\text { university faculty: } \\
\text { an interaction } \\
\text { between subjective } \\
\text { sleep quality and } \\
\text { the OXTR } \\
\text { rs2268498 } \\
\text { polymorphism }\end{array}$ & $\begin{array}{l}\text { Jiao Wu } \\
(2020)\end{array}$ & $\begin{array}{l}575 \text { professores } \\
\text { universitários } \\
\text { para análise de } \\
\text { Burnout e } \\
\text { Sono, dos quais } \\
376 \text { foram } \\
\text { analisados } \\
\text { quanto ao gene }\end{array}$ & $\begin{array}{l}\text { Explorar os } \\
\text { efeitos da } \\
\text { qualidade do } \\
\text { sono, } \\
\text { polimorfismo } \\
\text { funcional OXTR } \\
\text { rs2268498 e suas } \\
\text { interações com o } \\
\text { Burnout }\end{array}$ & $\begin{array}{l}\text { O polimorfismo rs } 2268498 \text { OXTR } \\
\text { e a qualidade do sono interagiram } \\
\text { para afetar as dimensões de } \\
\text { exaustão emocional e cinismo do } \\
\text { Burnout, sugerindo um nível mais } \\
\text { alto de exaustão emocional e } \\
\text { cinismo nos portadores do alelo C } \\
\text { do que nos homozigotos T em } \\
\text { condições de baixa qualidade do } \\
\text { sono. }\end{array}$ \\
\hline
\end{tabular}




\begin{tabular}{|c|c|c|c|c|}
\hline $\begin{array}{l}\text { Qualidade do sono } \\
\text { e fatores } \\
\text { associados entre } \\
\text { docentes de } \\
\text { educação } \\
\text { superior }^{21}\end{array}$ & $\begin{array}{c}\text { Aline } \\
\text { Macedo } \\
\text { Carvalho } \\
\text { Freitas }(2021)\end{array}$ & $\begin{array}{l}408 \text { docentes } \\
\text { do ensino } \\
\text { superior }\end{array}$ & $\begin{array}{c}\text { Estimar a } \\
\text { prevalência e os } \\
\text { fatores associados } \\
\text { à qualidade do } \\
\text { sono ruim entre } \\
\text { docentes de } \\
\text { educação superior } \\
\text { de uma } \\
\text { universidade } \\
\text { pública na Bahia }\end{array}$ & $\begin{array}{l}\text { Houve alta proporção de qualidade } \\
\text { do sono ruim entre os docentes. A } \\
\text { ausência e/ou irregularidade da } \\
\text { prática de lazer, o tempo de sono } \\
\text { menor ou igual a seis horas, as } \\
\text { queixas de dor musculoesquelética } \\
\text { e de dor de cabeça, e a experiência } \\
\text { de alta exigência no trabalho são } \\
\text { fatores associados à maior } \\
\text { prevalência da qualidade do sono } \\
\text { ruim entre os docentes. }\end{array}$ \\
\hline
\end{tabular}

Fonte: Elaboração Própria.

\section{Discussão}

No presente estudo possibilitou-se evidenciar a ocorrência de alterações do sono em professores universitários de diversas áreas, bem como observar as diferentes causas e repercussões dessas alterações em seu cotidiano.

À primeira análise, notou-se a escassez de estudos em âmbito mundial em relação a essa problemática. Mesmo ampliando o recorte temporal e buscando-se em diversas bases de dados, com os descritores oficiais e suas sinonímias, apenas cinco estudos foram elegíveis para esta revisão. Parte disso deve-se ao fato de muitos estudos emergirem relacionados a professores de ensino médio ou infantil e outros terem como foco os estudantes. Além disso, alguns estudos que foram excluídos em última análise apresentavam erros estatísticos elementares ou baixo rigor metodológico.

Ademais, notou-se a ausência de estudos com maior nível de evidência que poderiam contribuir para a compreensão dessa problemática, o que reflete uma constatação importante da fragilidade e das lacunas nesse aspecto da saúde do trabalhador.

Nesta revisão predominaram os estudos realizados no Brasil ${ }^{20-22,24}$ e com professores universitários das diversas áreas do conhecimento ${ }^{22-24}$, sendo um estudo específico com professores atuantes na formação stricto sensu ${ }^{20}$ e um outro apenas com docentes da área de saúde ${ }^{21}$.
Três estudos ${ }^{20,21,23}$ utilizaram o PSQI para avaliar a qualidade subjetiva do sono. Trata-se de um instrumento que avalia a qualidade do sono por meio de um questionário padronizado, num intervalo de tempo de um mês. O PSQI permite a análise dos padrões de sono, quantifica a qualidade subjetiva do sono e episódios de distúrbios do sono, contendo 19 questões agrupadas em sete componentes. Os escores menores ou iguais a cinco indicam boa qualidade de sono e escores maiores que cinco indicam má qualidade do sono. ${ }^{25}$

Um estudo ${ }^{22}$ utilizou a Escala de Sonolência de Epworth (ESS) para avaliar a sonolência diurna, um dos mais frequentes distúrbios do sono atualmente. Trata-se de um questionário autoaplicável que avalia a probabilidade de adormecer em oito situações envolvendo atividades diárias, algumas delas altamente soporíficas. $\mathrm{O}$ escore global varia de 0 a 24, sendo que os escores acima de dez sugerem o diagnóstico de sonolência diurna excessiva ${ }^{26}$.

Um outro estudo ${ }^{24}$ avaliou os dados de sono por meio do Mini-Sleep Questionnaire (MSQ), constituído por dez questões, em que as pontuações mais altas caracterizam uma pior qualidade do sono. A soma total dos escores é dividida em quatro níveis: dez a 24 pontos indicam sono bom; de 25 a 27 pontos, sono levemente alterado; 28 a 30 pontos, sono moderadamente alterado; e $\geq 31$, sono muito alterado ${ }^{27}$.

As alterações do sono podem manifestar-se de maneiras diversificadas, uma vez que configuram uma condição 
multifatorial. Num estudo brasileiro, realizado em Goiás ${ }^{21}$, a sonolência diurna, os distúrbios do sono e a duração do sono foram fatores que mais contribuíram para a redução na qualidade subjetiva de sono em professores da área de saúde, o que predominou em 57,9\% dos participantes. A sonolência diurna prevaleceu em $35,2 \%$ dos participantes de um outro estudo brasileiro realizado no Rio Grande do $\mathrm{Sul}^{22}$.

Houve, também, prevalência de $65,8 \%$ de má qualidade do sono em professores atuantes em stricto sensu da região sul do $\mathrm{Brasil}^{20}$, e em $61,3 \%$ dos docentes participantes de um estudo brasileiro realizado na Bahia $^{24}$. Nesse último estudo, a dificuldade em adormecer, acordar cansado e acordar com dor de cabeça foram as principais manifestações da má qualidade do sono.

O estudo realizado na China, em Pequim $^{23}$ foi o único em que a má qualidade de sono não prevaleceu, ocorrendo em, aproximadamente, um quarto da população estudada. Nesse estudo, também, não houve diferenças significantes na comparação da qualidade de sono entre dados sociodemográficos e ocupacionais, como o gênero, idade, nível de formação e posição em que ocupa na universidade, embora, proporcionalmente, mais bacharéis apresentavam baixa qualidade de sono que os professores com formação stricto sensu. Esses achados são corroborados pelo estudo brasileiro rio-grandense ${ }^{22}$, em que nenhuma característica ocupacional e sociodemográfica teve influência significativa na sonolência diurna excessiva.

Entretanto, os professores de pósgraduação stricto sensu ${ }^{20}$ demonstraram que a influência negativa do ritmo e intensidade do trabalho, alto trabalho excessivo, workaholism e o trabalho excessivo e compulsivo contribuíram para a percepção de qualidade de sono ruim. Nesse estudo em específico, foi atribuído que as pressões por publicações científicas, a bolsa-produtividade e o desenvolvimento de múltiplos projetos concomitantes exercem papel fundamental nas características de workaholism, que foi fator significante para a redução da qualidade do sono nessa população ${ }^{20}$. Ademais, os componentes mais afetados, relacionados à qualidade de sono, nessa população foram, além da qualidade subjetiva do sono, a latência do sono, a duração do sono, distúrbios do sono e a sonolência diurna, pois estavam significativamente associados ao trabalho excessivo ${ }^{20}$

A qualidade de sono foi também prejudicada em professores universitários no estudo baiano ${ }^{24}$, em que os autores buscaram relacioná-la a aspectos ocupacionais no modelo demanda-controle. Neste estudo, os professores que tinham mais de um vínculo profissional, bem como os que apresentavam tempo irregular ou insuficiente para o lazer, trabalho passivo ou de alta exigência e os que dormiam seis horas ou menos evidenciaram menor qualidade de sono. Além disso, aspectos físicos como queixas de dor na coluna ou musculoesquelética e dor de cabeça associaram-se significativamente à qualidade de sono ruim ${ }^{24}$. Neste estudo, a aplicação da avaliação da percepção do trabalho pelo modelo demanda-controle torna a avaliação mais robusta, pois o trabalho de alta exigência, conforme citado pelos autores, é a combinação de alta demanda e baixo controle no trabalho, considerado um modelo, que gera alto desgaste do profissional ${ }^{28}$.

Com isso, é possível interpretar que, tanto o workaholism e seus aspectos correspondentes $^{20}$, quanto o alto desgaste profissional determinado por trabalho de alta exigência ${ }^{24}$, podem acarretar em prejuízos à qualidade de sono e seus componentes em professores universitários.

A sonolência diurna foi associada à redução da qualidade de vida de professores universitários, bem como à redução de todos os seus domínios em outro estudo riograndense $^{23}$. Os aspectos fisiológicos e comportamentais que se relacionam à qualidade de vida podem ser afetados pelas alterações do sono, devido às alterações 
homeostáticas, imunológicas, adaptativas e mentais determinadas que são reguladas pelo sono adequado ${ }^{23}$. Isso indicou, neste estudo, o quanto a redução nos aspectos do sono de boa qualidade podem repercutir na qualidade de vida de professores universitários.

O estresse laboral, bem como a sua influência na redução da qualidade do sono foram avaliados no estudo goiano ${ }^{21}$, porém predominaram baixos níveis de estresse nessa população e não houve significância estatística na associação dessas variáveis, exceto no que tange ao uso de medicamentos para dormir. Os professores que apresentavam maiores níveis de estresse no trabalho apresentavam pior qualidade de sono com relação à necessidade de uso de medicação para dormir. Ainda assim, a correlação foi de moderada intensidade ${ }^{21}$

No estudo chinês ${ }^{23}$, os autores buscaram associar a qualidade subjetiva do sono e o polimorfismo do gene OXTR rs2268498 na ocorrência de Síndrome de Burnout, buscando explicar potenciais correlações genéticas e neuroendócrinas dessa síndrome. O OXTR é um gene receptor de ocitocina, um mediador amplamente aceito na regulação da cognição e do comportamento social. O polimorfismo rs2268498 é um polimorfismo funcional do gene OXTR, intimamente associado ao funcionamento social. Na primeira etapa deste estudo, houve associação positiva entre a qualidade subjetiva do sono e a exaustão emocional e o cinismo entre os docentes universitários, o que demostra a influência da qualidade de sono na ocorrência de alguns aspectos do Burnout. Na análise genômica, o alelo $\mathrm{C}$ do polimorfismo OXTR rs2268498 modulou a influência da qualidade de sono na ocorrência do Burnout ${ }^{23}$. Entretanto, os próprios autores desse estudo consideramno como piloto, não havendo, nas buscas para esta revisão, outros artigos para estabelecer comparação. Ainda assim, é possível inferir que a qualidade de sono impactou na ocorrência de sintomas de Burnout nessa população.

Os estudos para esta revisão apresentaram diversas limitações, inicialmente pelo fato de todos serem transversais, ou seja, um desenho metodológico em que os desfechos e as exposições são avaliadas simultaneamente, gerando um nível de evidência 4 (baixo) ${ }^{19}$. Além disso, as associações da qualidade de sono foram realizadas com variáveis independentes diversas, o que impossibilitou uma comparação mais profunda das evidências nesta revisão.

Individualmente, o estudo goiano ${ }^{21}$ limita-se devido à pequena amostra avaliada e, utiliza um instrumento menos difundido para a análise da qualidade do sono (MSQ), quando a maioria dos estudos dessa natureza baseiam-se no PSQI, por ser um instrumento mais completo, contemplando diversos interligados sobre o processo de dormir e acordar.

O estudo chinês ${ }^{23}$, por ser um estudo piloto, traz poucas comparações e asserções referentes, especificamente, aos professores universitários e, embora a amostragem seja representativa, esse estudo se concentrou em apenas uma única universidade de um único local geográfico, o que impede maiores inferências generalizadas sobre os aspectos genéticos.

Todos os estudos indicaram a necessidade de estudos futuros com delineamento metodológico mais robusto, como a análise objetiva do sono por polissonografia ou actigrafia, pesquisas experimentais e prospectivas, a fim de obter-se resultados mais contundentes e que proporcionem o desenvolvimento de estratégias mais assertivas para o cuidado da saúde do sono dos professores universitários.

\section{Conclusão}

Conclui-se que as alterações do sono em professores universitários foram caracterizadas, sobretudo, por redução da qualidade subjetiva do sono e sonolência diurna. A qualidade subjetiva do 
sono pode ainda ser caracterizada pela dificuldade em adormecer, cansaço ao acordar e redução da duração do sono. Vários aspectos relacionados ao trabalho do professor universitário influenciaram na qualidade do sono, como jornadas extensas, o trabalho excessivo, workaholism e a alta exigência no trabalho. Além disso, a redução na qualidade do sono e a sonolência diurna influenciaram nas percepções de qualidade de vida e em aspectos ligados ao Burnout.

Esta revisão evidenciou, também, que há uma escassez significativa de estudos considerando os aspectos da saúde do sono de professores universitários, pois, mesmo com um recorte temporal de 20 anos, poucos estudos emergiram como elegíveis dentro dos critérios estabelecidos neste estudo. Isso torna imprescindível a busca por dados científicos robustos, explorando amplamente as alterações de sono em professores universitários e monitorando suas repercussões, pois, somente por esse caminho, será possível estabelecer medidas de promoção de saúde no âmbito do trabalho docente.

\section{Referências Bibliográficas}

1. Valle LER, Reimão R, Malvezzi S. Reflexões sobre psicopedagogia, estresse e distúrbios do sono do professor. Rev. Psicopedagogia. 2011;28(87):237-45. Available from: $\quad$ http://pepsic.bvsalud.org/scielo.php?script=sci_arttext\&pid=S010384862011000300004

2. Kovess-Masféty V, Sevilla-Dedieu C, Rios-Seidel C, Nerrière E, Chan Chee C. Do teachers have more health problems? Results from a French cross-sectional survey. BMC Public Health 2006; 6(101):1-13. Available from: https://bmcpublichealth.biomedcentral.com/articles/10.1186/1471-2458-6-101

3. Oliveira ERA, Garcia AL, Gomes MJ, Bittar TO, Pereira AC. Gênero e qualidade de vida percebida - estudo com professores da área de saúde. Ciência \& Saúde Coletiva. 2012;17(3):741,7. DOI: https://doi.org/10.1590/S1413-81232012000300021

4. Acosta-Fernández M, Parra-Osório L, Molina CB, Aguilera-Velasco MA, PozosRadillo BE. Estrés laboral, burnout, salud mental y su relación con violencia psicológica en docentes universitários. Salud Uninorte. 2019;35(3):328-42. Available from: https://www.redalyc.org/articulo.oa?id=81763959003

5. Leite AF, Nogueira JA. Health conditioning factors work-related to health professors: an integrative review. Rev Bras Saúde Ocup. 2017;42:e6. DOI: https://doi.org/10.1590/2317-6369000010116

6. Spagnoli P, Balducci C, Scafuri Kovalchuk L, Maiorano F, Buono C. Are engaged workaholics protected against job-related negative affect and anxiety before sleep? a study of the moderating role of gender. Int J Environ Res Public Health. 2018 Sep;15(9):1996. DOI: https://10.3390/ijerph15091996

7. Tubbs AS, Dollish HK, Fernandez F, Grandner A. The basics of sleep physiology and behavior. In: Grandner A, editor. Sleep and Health. London: Academic Press - Elsevier; 2019; p. 3-10. DOI: https://doi.org/10.1016/B978-0-12-815373-4.00001-0 
8. Suni E, Rehman A. Sleep Dictionary. Sleep Foundation, 2021. Available from: https://www.sleepfoundation.org/how-sleep-works/sleep-dictionary

9. Kim LJ, Tufik S, Andersen ML. Neurofisiologia do Sono. In: Haddad FLM, Gregório LC, editores. Manual do residente: medicina do sono. Barueri: Manole; 2017

10. Maslach C, Schaufeli WB, Leiter MP. Job Burnout. Annual Review of Psychology. 2001;52:397-422. DOI: https://doi.org/10.1146/annurev.psych.52.1.397

11. Sanchez HM, Sanchez EGM, Barbosa MA, Guimarães EC, Porto CC. Impact of health on quality of life and quality of working life of university teachers from different areas of knowledge. Ciência \& Saúde Coletiva. 2019;24(11): 4111-22. DOI: https://doi.org/10.1590/1413-812320182411.28712017

12. Gluschkoff K, Elovainio M, Kinnunen U, Mullola S, Hintsanen M, KeltikangasJärvinen L, et al. Work stress, poor recovery and burnout in teachers. Occup Med (Lond). 2016;66(7):564-70. DOI: https://10.1093/occmed/kqw086

13. Santos CMC, Pimenta CAM, Nobre MRC. A estratégia PICO para a construção da pergunta de pesquisa e busca de evidências. Rev Latino-Am Enfermagem. 2007; 15(3). DOI: https://doi.org/10.1590/S0104-11692007000300023

14. Mendes KDS, Silveira RCCP, Galvão CM. Revisão integrativa: método de pesquisa para a incorporação de evidências na saúde e na enfermagem. Texto Contexto Enf. 2008;17(4):758. DOI: https://doi.org/10.1590/S0104-07072008000400018

15. Whittemore R, Knafl K. The integrative review: updated methodology. J Adv Nurs. 2005;52(5):546-53. DOI: https://doi.org/10.1111/j.1365-2648.2005.03621.x

16. Moher D, Liberati A, Tetzlaff J, Altman DG. The PRISMA GROUP. Preferred reporting items for systematic reviews and meta-analyses: The PRISMA statement. International Journal of Surgery [Internet]. 2010; 8(5):336-41. DOI: https://doi.org/10.1016/j.ijsu.2010.02.007

17. Mourad Ouzzani, Hossam Hammady, Zbys Fedorowicz, Ahmed Elmagarmid. Rayyan - a web and mobile app for systematic reviews. Systematic Reviews. 2016; 5:210, DOI: https://10.1186/s13643-016-0384-4

18. Joanna Briggs Institute (JBI). JBI Checklist for Analytical Cross Sectional Studies. JBI Global, 2020. Available from: https://jbi.global/critical-appraisal-tools

19. Souza MT, Silva MD, Carvalho, R. Integrative review: what is it? How to do it? Einstein [Internet]. 2010; 8(1):102-6. DOI: https://doi.org/10.1590/s1679-45082010rw1134

20. Cardoso MG, Mesas AE, Cardelli AAM, Galdino MJQ, Barreto MFC, Aroni P, et al. Qualidade do sono e workaholism em docentes de pós-graduação stricto sensu. Acta Paul Enferm. 2020;;33:eAPE20190228. DOI: http://dx.doi.org/10.37689/actaape/2020AO02285 
21. Sousa AR, Santos RB, Silva RM, Santos CCT, Lopes VC, Mussi FC. Occupational stress and sleep quality in professor of the health area. Rev Rene. 2018; 19:e33088. DOI: https://10.15253/2175-6783.20181933088

22. Amaro JMRS, Dumith SC. Sonolência diurna excessiva e qualidade de vida relacionada à saúde dos professores universitários. J Bras Psiquiatr. 2018;67(2):94-100. DOI: https://10.1590/0047-2085000000191

23. Wu J, Dong Y, Zhao XR, He SC, Zhang XY. Burnout in university faculty: an interaction between subjective sleep quality and the OXTR rs2268498 polymorphism. Journal of Affective Disorders. 2020;276:927-35. DOI: https://doi.org/10.1016/j.jad.2020.07.094

24. Freitas AMC, Araújo TM, Pinho PS, Sousa CC, Oliveira PCS, Souza FO. Qualidade do sono e fatores associados entre docentes de educação superior. Rev Bras Saúde Ocup. 2021;46:e2. DOI: http://dx.doi.org/10.1590/2317-6369000018919

25. Bertolazi AN, Fagondes SC, Hoff LS, Dartora EG, Miozzo ICS, Barba MEF, et al. Validation of the Brazilian Portuguese version of the Pittsburgh Sleep Quality Index. Sleep Med. 2011;12:70-5. DOI: https://10.1016/j.sleep.2010.04.020

26. Bertolazi AN et al. Validação da escala de sonolência de Epworth em português para uso no Brasil. J. Bras. Pneumol. [online]. 2009;35(9):877-83; DOI: https://doi.org/10.1590/S1806-37132009000900009

27. Falavigna A, Bezerra MLS, Teles AR, Kleber FD, Velho MC, Silva RC, et al. Consistency and reliability of the Brazilian Portuguese version of the Mini-Sleep Questionnaire in undergraduate students. Sleep Breath. 2011;15:351-5. DOI: https://10.1007/s11325-010-0392-x

28. Araújo TM, Karasek RA. Validity and reliability of the job content questionnaire in formal and informal jobs in Brazil. Scand J Work Environ Health. 2008;34(6):52-9. Available from: https://www.researchgate.net/publication/41464059

\section{APÊNDICE 1}

Apêndice 1: Estratégia de busca nas bases de dados, de acordo com os descritores DeCS/MeSH. Campinas, São Paulo, Brasil - 2021.

\begin{tabular}{|c|l|}
\hline Base & \multicolumn{1}{c|}{ Descritor } \\
\hline \multirow{3}{*}{$\begin{array}{c}\text { Scopus, WoS, PubMed } \\
\text { (MedLine), BVS }\end{array}$} & "Faculty" OR "University Professor" AND "Sleep Deprivation" OR \\
& "Inadequate Sleep" OR "Insufficient Sleep" OR "Insufficient Sleep Syndrome" \\
& OR "Sleep Insufficiency" \\
\cline { 2 - 3 } & "Faculty" OR "University Professor" AND "Sleep" OR "Sleep Habits" OR \\
& "Sleeping Habit" OR "Sleeping Habits" \\
\hline
\end{tabular}




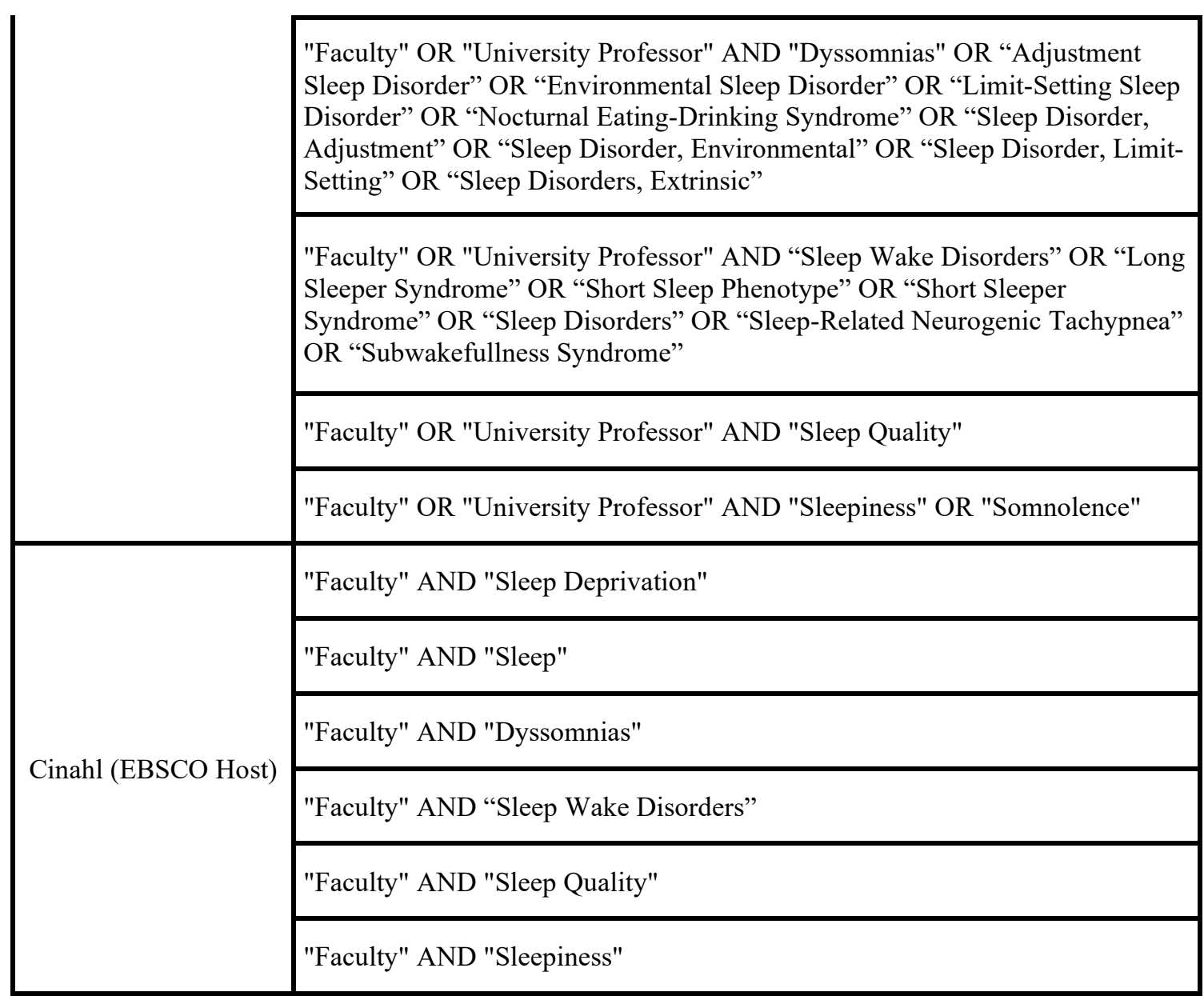

WoS: Web Of Science; BVS: Biblioteca Virtual em Saúde

Fonte: Elaboração Própria.

\section{Como citar este artigo:}

Moraes BFM, Salvi CPP, Martino MMF. Alterações do sono em professores universitários: uma revisão integrativa. Rev. Aten. Saúde. 2021; 19(70): 123-137. 